\title{
Application of micro expansion cement in Pavement Base
}

\author{
Li Hongjun \\ College of Road and Rail, Hubei Communications Technical Co5llege, Wuhan, China Zip Code: 430079
}

\begin{abstract}
Cement stabilized macadam base is widely used as a road building material in various grades of highways. Based on the law that the base cracking is mainly affected by the shrinkage of cement stabilization materials, this paper introduces the method of adding micro-expanding cement to the base that can effectively reduce the hydration shrinkage coefficient and dryness shrink factor. At the same time, it is pointed out that strict control of the amount of micro-expansion cement and the quality of the construction can also effectively reduce the occurrence of cracks in the base.
\end{abstract}

\section{Preface}

Cement stabilized macadam base is a kind of aggregate gap formed by filling Graded Macadam with a certain amount of cementitious materials and enough mortar, and paves and compacts the pavement structure layer according to the principle of inlay and extrusion [1]. Cement stabilized macadam base has the advantages of high strength, high rigidity and good water stability. However, due to the inherent dry shrinkage and temperature shrinkage characteristics of cement stabilized materials, cracks are easy to occur in this kind of base. The formation of cracks in the base course will affect the stability and performance. The reflection crack caused by the cracking of cement stabilized macadam base is also one of the main failure forms of asphalt pavement [2].

The compactness of cement stabilized macadam base is close to the compactness, and the strength is mainly formed by the inlaying and locking of macadam. Its initial strength is high, and its strength increases with age. Cement stabilized macadam base can form plate quickly, with high strength, good impermeability and frost resistance. The cement content of cement stabilized macadam is generally $3 \%-6 \%$. The surface of cement stabilized macadam is solid, which is an ideal base material for high-grade pavement.

The base layer plays the role of supporting surface layer. The stability of the foundation has a very important influence on the stability of the surface layer. In order to obtain a stable base course, the design and construction of the base course should be comprehensively considered from the raw materials, gradation, cement dosage, water content, admixture and health preservation of the base course. By reducing the shrinkage of cement stabilized soil mixture, the cracking of cement stabilized macadam base can be reduced.

In order to reduce the dry shrinkage of cement stabilized macadam base, two technical measures are often taken. First, the grass-roots timely health. After the completion of the construction of the base course, it is necessary to timely maintain the moisture and maintain the health, and lay the lower seal layer and the asphalt lower layer as soon as possible to reduce the evaporation of the water in the base course. Second, the rational use of additives in the grass-roots. The shrinkage deformation of cement stabilized macadam is reduced by adding additives.

\section{Properties of micro expansion cement}

Generally, the strength grade of cement used for cement stabilized macadam base shall not be less than $32.5 \mathrm{mpa}$, and shall meet the requirements of technical rules for construction of highway pavement base. Fineness and soundness of cement shall meet the requirements of specifications. At the same time, the initial setting time of cement shall be more than $3 \mathrm{~h}$, and the final setting time shall not be less than $6 \mathrm{~h}$.

The physical performance indexes of micro expansion are shown in Table 1.

Table 1. physical index of micro expansion cement

\begin{tabular}{|c|c|c|c|}
\hline Testing items & $\begin{array}{c}\text { Unit of } \\
\text { measurement }\end{array}$ & $\begin{array}{c}\text { detection } \\
\text { result }\end{array}$ & $\begin{array}{c}\text { Standard } \\
\text { requirements }\end{array}$ \\
\hline Stability & $\mathrm{mm}$ & 0.7 & $\leqslant 5$ \\
\hline $\begin{array}{c}\text { Initial setting } \\
\text { time }\end{array}$ & $\min$ & 245 & $\geqslant 180$ \\
\hline $\begin{array}{c}\text { Final setting } \\
\text { time }\end{array}$ & $\min$ & 540 & $\geqslant 360, \leqslant 600$ \\
\hline $\begin{array}{c}\text { 3-day } \\
\text { compressive } \\
\text { strength }\end{array}$ & $\mathrm{MPa}$ & 14.4 & $\geqslant 10$ \\
\hline $\begin{array}{c}\text { 3-day flexural } \\
\text { strength }\end{array}$ & $\mathrm{MPa}$ & 33.7 & $\geqslant 32.5$ \\
\hline $\begin{array}{c}\text { 28 day } \\
\text { compressive } \\
\text { strength }\end{array}$ & $\mathrm{MPa}$ & 9.4 & $\geqslant 5.5$ \\
\hline $\begin{array}{c}28 \text { day flexural } \\
\text { strength }\end{array}$ & $\mathrm{MPa}$ & & $\geqslant 2.5$ \\
\hline
\end{tabular}

\footnotetext{
* Corresponding author: Leehj2004@163.com
} 
The amount of cement used in cement stabilized macadam base must be appropriate. Too little cement will reduce the cementation effect, and too much cement will increase the hydration heat reaction temperature, and the strength is too high to form cracks.

Micro expansion cement has the characteristics of better early strength and micro expansion. This kind of cement can expand by the action of expansive agent during hydration, which makes up for the shrinkage of cement stabilized macadam, reduces the cracking of base course and improves the performance of pavement base course.

\section{Gradation of mixture}

According to the quality and source of the material, the mixture composition design test is carried out. Refer to table 2 for relevant grading standards. Select the most suitable mix proportion and measure the most suitable moisture content and maximum dry density by heavy compaction method [3]. By increasing the internal friction angle of aggregate, the strength of base can be improved, but the shrinkage of base will not be increased.

Table 2. gradation of cement stabilized macadam base

\begin{tabular}{|c|c|}
\hline $\begin{array}{c}\text { Mesh size } \\
(\mathbf{m m})\end{array}$ & $\begin{array}{c}\text { Mass percentage passing } \\
\text { through the sieve (\%) }\end{array}$ \\
\hline 31.5 & 100 \\
\hline 19 & $68 \sim 86$ \\
\hline 13.2 & $72 \sim 6$ \\
\hline 9.5 & $38 \sim 58$ \\
\hline 4.75 & $22 \sim 32$ \\
\hline 2.36 & $16 \sim 28$ \\
\hline 0.6 & $8 \sim 15$ \\
\hline 0.075 & $0 \sim 3$ \\
\hline
\end{tabular}

\section{Effect of micro expansion cement on the strength of base course}

Micro expansion cement is a kind of cement with micro expansion characteristics by adding expansion agent. The expansion agent is an additive that can make the cement expand. According to the different dosage, the expander can compensate shrinkage, micro expansion and produce self stress. At present, the commonly used expansion agents are mainly divided into two categories: Cao or $\mathrm{MgO}$ and Ettringite. Because of the stable performance of ettringite expansion agent, it is the main type used at present. Ettringite expansion agents can be divided into alunite, calcium sulphoaluminate, UEA and nearly ten kinds of compound with lime and gypsum. The main mechanism is to use calcium aluminate in sulfate cement to produce calcium aluminate with high sulfur content. The solid volume will expand to 2.5 times of the original volume due to the formation of calcium aluminate with high sulfur content.

Micro expansion cement can compensate the shrinkage caused by cement hydration of cement stabilized macadam base. The micro expansion can be achieved by properly increasing the content of Cao and slag in cement. In the process of cement hydration, calcium oxide generates calcium hydroxide, which produces volume expansion and compensates shrinkage. The strength of cement increases slowly under the alkali excitation of calcium hydroxide.

The influence of micro expansion cement and ordinary portland cement on the strength of base course is compared by experiment. In the test, the cement dosage was $4.5 \%$, and the base course was graded by skeleton. The standard curing conditions are temperature $20 \pm 2{ }^{\circ} \mathrm{C}$, humidity over $95 \%$. The compressive strength was measured 7 days after standard curing. The change of shrinkage coefficient of base course under different curing conditions was compared. The first type of health preservation is standard health preservation for 28 days. The second type of health preservation is 7 days after standard health preservation and 21 days under outdoor natural conditions. Measure the shrinkage coefficient with dial indicator. See Table 3 for test results.

Table 3. test results of the influence of cement varieties on the base course

\begin{tabular}{|c|c|c|c|}
\hline \multicolumn{2}{|c|}{ Testing items } & $\begin{array}{l}\text { Micro } \\
\text { expansion } \\
\text { cement }\end{array}$ & $\begin{array}{l}\text { Ordinary } \\
\text { portland } \\
\text { cement }\end{array}$ \\
\hline \multicolumn{2}{|c|}{$\begin{array}{l}\text { Optimum moisture } \\
\text { content }(\%)\end{array}$} & 5.4 & 5.4 \\
\hline \multicolumn{2}{|c|}{$\begin{array}{l}\text { Maximum dry density } \\
(\mathrm{g} / \mathrm{cm} 3)\end{array}$} & 2.345 & 2.342 \\
\hline \multicolumn{2}{|c|}{$\begin{array}{l}\text { 7-day compressive } \\
\text { strength (Mpa) }\end{array}$} & 3.9 & 4 \\
\hline \multirow{2}{*}{$\begin{array}{c}28 \text { day } \\
\text { contraction } \\
\text { coefficient } \\
\left(\times 10^{-6}\right)\end{array}$} & $\begin{array}{l}\text { The first } \\
\text { condition } \\
\text { for health } \\
\text { preservation }\end{array}$ & 10.5 & 18.5 \\
\hline & $\begin{array}{l}\text { The second } \\
\text { condition of } \\
\text { health } \\
\text { preservation }\end{array}$ & 29 & 36.5 \\
\hline
\end{tabular}

The following conclusions can be drawn from the analysis of test results:

(1) the optimum moisture content, maximum dry density and 7-day compressive strength of the two cement stabilized base structures are similar.

(2) under the first curing condition, the shrinkage coefficient of micro expansion cement is $56.7 \%$ of that of ordinary portland cement. This is because the shrinkage of cement under this condition is mainly the shrinkage of cement hydration itself. Micro expansion cement can obviously reduce the hydration shrinkage of the base course.

(3) under the second curing condition, the shrinkage coefficient of micro expansion cement is $79.5 \%$ of that of ordinary silicon cement. This is because the cement shrinkage is mainly hydration shrinkage and dry shrinkage. It can be seen that micro expansion cement can significantly reduce the base dry shrinkage. 


\section{Base construction}

Cement hydration needs setting time, which is divided into initial setting and final setting [4]. The initial setting time of the base cement should be more than 3 hours, and the final setting time is more than 6 hours and less than 10 hours. When the cement stabilized macadam base is constructed, the compaction shall be completed at the final setting of the cement. At the same time, after the technical indicators are qualified, carry out curing.

\subsection{Mixing of mixture}

Centralized plant mixing shall be adopted for mixing. Before using the plant mixing equipment, the plant mixing equipment and each metering system shall be debugged to make the water content, aggregate grading and cement content of the mixed mixture meet the requirements of proportioning, make the machine operate normally, and make the output of the mixer consistent with the production capacity of the used paver.

The mixing process mainly controls the mixture gradation, water content and cement dosage. At the same time, it should be considered that there is water loss in the process of transportation and rolling. The mixing of the mixture shall avoid the uneven and segregation of the coarse and fine aggregate. After mixing, samples need to be collected to check whether the mixture ratio is consistent with the design. During the mixing process, it is necessary to check the mixing condition every one or two hours.

\subsection{Paving}

Before paving, the subbase shall be watered and wetted, and the mixture shall be paved according to the loose paving coefficient determined during the paving of the test road section. Check the operation of each part of the paver before paving. Strictly control the thickness, elevation and cross slope of the base course to meet the design requirements. The paver must pave continuously. When the paver paves, it shall be spread at a uniform speed, and it is forbidden to stop the paver to wait for materials.

Use two pavers to pave side by side. The speed, paving thickness, coefficient of loose paving, crown slope, paving integrity and vibration frequency shall be consistent before and after. The paving lap width shall be moderate to ensure that the joint is flat. The paving construction must follow the principles of high rather than low and better than scratch. The distance between the front and back of two pavers should not be more than $10 \mathrm{~m}$. The longitudinal direction of the two construction sections shall be overlapped by $300-400 \mathrm{~mm}$. The paving width of each paver shall not exceed $7.5 \mathrm{~m}$, and the overlapping position of the two pavers shall avoid the wheel track belt of the lane and be placed in the center of the lane as far as possible. Two pavers work at the same time and keep moving at a constant speed. The slope of the screed crown of the paver shall be the same. The half width of the pavement is paved at one time. Partial coarse and fine aggregate segregation on the pavement during paving should be eliminated in time. The transport vehicle shall be parked $20-30 \mathrm{~cm}$ in front of the paver. During the paving construction, the dumper shall not collide with the paver.

\subsection{Roller compaction}

After each paver, the steel wheel roller shall be followed for initial compaction. Static pressure is adopted for initial pressure. In order to prevent the loss of moisture in the mixture, the length of primary rolling shall be controlled at $50-80 \mathrm{~m}$. The rolling section must be in the shape of ladder with clear layers and clear demarcation marks.

The rolling shall be carried out according to the sequence of static pressure, weak vibration rolling and strong vibration rolling. Roller rolling shall overlap 30$50 \mathrm{~cm}$ each time. The running speed of the first to second pass roller is $1.5 \mathrm{~km} / \mathrm{h}$. After that, the running speed of the roller is $2.5 \mathrm{~km} / \mathrm{h}$. The parking position of roller shall be staggered for more than $3 \mathrm{~m}$, and it shall be parked on the road section that has been rolled to avoid damaging the base structure. It is strictly prohibited for the roller to turn around and brake sharply on the completed or rolling road section.

The speed and times of rolling shall be subject to the data provided by the test section. In case of soft elastic phenomenon in the rolling process, the mixture in this road section shall be excavated in time, and the new material shall be replaced for rolling. The surface after rolling shall be flat and free of wheel trace [5].

\subsection{Regimen}

After the cement stabilized base is rolled and tested to be qualified, it can be cured. Polyester geotextile or film can be used for curing. During the curing period, the surface of the base course shall be kept moist, usually for 7 days. When the cement stabilized base does not reach a certain strength, vehicles are not allowed to pass.

Sprinkler with water sprinkler health, sprinkler sprinkler spray type, prohibit the use of high-pressure nozzle, so as not to damage the basic structure. The times of watering every day shall be determined by the climate, and the surface of cement stabilized macadam shall be kept moist throughout the curing period.

\section{Conclusion}

According to the use of micro expansion cement in the base course, micro expansion cement has the function of compensating the shrinkage of cement stabilized macadam base course material. The hydration shrinkage coefficient of cement stabilized macadam is only $56.7 \%$ of that of ordinary portland cement. The dry shrinkage coefficient of cement stabilized macadam base with micro expansion cement is only $79.5 \%$ of that of ordinary portland cement. Micro expansion cement can effectively reduce the base cracking. 
The use of micro expansion cement can make the deformation of cement stabilized macadam base in the whole drying shrinkage period and curing period relatively stable. The use of micro expansion cement can effectively control the dry shrinkage crack of cement stabilized macadam base. But the dosage of micro expansion cement should be strictly controlled when using. When the dosage of micro expansion cement is too much, it will cause the expansion and cracking of the base structure, which is easy to cause structural damage.

\section{References}

1. Q.Y.Song, How to reduce cracks in cement stabilized macadam base ,Traffic world, 12: 42-43+ 25 (2017)

2. X.J.Cui, X.P.Shi,Y.C.Gong,Prevention and treatment of cracks in cement stabilized macadam base pavement, Northern transportation, 05: 5658(2017)

3. Y.Z.Huo,X.M.Huang,Research on the application technology of micro expansion cement stabilized macadam in the base of high-grade highway, Journal of Inner Mongolia Agricultural University (Natural Science Edition).,01 : 163-169 (2009)

4. J.Zhang,L.Y.Wei,T.Wang,Study on micro cracking technology of cement stabilized macadam base material, Highway, 01: 8-13(2017)

5. A.Y.Shi,Analysis and prevention measures of cracks in cement stabilized macadam base,Transportation world ,8: 16-17(2019) 